http://jmscr.igmpublication.org/home/ ISSN (e)-2347-176x ISSN (p) 2455-0450

crossref DOI: https://dx.doi.org/10.18535/jmscr/v9i3.40

\title{
Effectiveness of Surged Faradic Current and Myofascial Release Technique on Lower Limb Muscles in Spastic Cerebral Palsy Patient" - A Case Study
}

\author{
Authors \\ Vijal Mewada ${ }^{*}$, Karishma Barot ${ }^{2}$, Charmi Patel ${ }^{3}$, \\ Vidhya Solanki ${ }^{4}$, Priyanka Chaudhari ${ }^{5}$ \\ ${ }^{1}$ BPT Intern, ${ }^{2,3,4,5}$ Tutor \\ 1,2,3,4,5 Nootan College of Physiotherapy, Sankalchand Patel University, Visnagar, Gujarat, India. 384315 \\ *Corresponding Author \\ Vijal Mewada
}

\begin{abstract}
Background: Cerebral Palsy is described as group of permanent disorder causing activity limitation in developing infant. Spasticity is a motor disorder causing increase stretch reflex with exaggerated tendon jerks. Myofascial Release Technique is the aid to mechanical, neural and psycho-physiological adaptation in the myofascial system. Faradic currents are surged having low pulse duration, hence used to treat innervated muscles.

Purpose: To find out the effectiveness of Surged Faradic Current and Myofascial Release technique on spasticity of lower limb muscles in a cerebral palsy patient.

Methodology: A case study was done from $14^{\text {th }}$ December 2020 to $9^{\text {th }}$ January 2021. A 4 year old male child diagnosed with spastic cerebral palsy's, pre and post treatment measures, data of Modified Ashworth Scale, Pediatric Manual Muscle Testing and Gross Motor Function-66 were evaluated and mentioned. MFR and SF was given to the calf, hamstring and adductor muscles for 3 days a week for 4 weeks.

Result: Gross Motor Function Scale, Pediatric Muscle Score and Modified Ashworth Scale improved after the intervention in this patient.

Conclusion: SF and MFR along with conventional rehabilitation was effective in case of spastic cerebral palsy subject.

Keywords: Cerebral Palsy, Myofascial Release Technique, Spasticity, Surged faradic Current.
\end{abstract}

\section{Introduction}

Cerebral Palsy is a group of disorders in the development of the infants movement and posture by causing activity limitation in the brain of a developing infant. The motor disorders accompany by the disturbance in sensation, perception, cognition, communication and behavior due to epilepsy and musculoskeletal problem. ${ }^{1}$ Due to nonprogressive damage of brain in early life, it is a condition which is characterized by motor dysfunction and also termed as static encephalopathy, because even when the primary lesion is static, changes are observed in the clinical pattern due to growth and development. ${ }^{2}$ The current worldwide prevalence in children between 3 to 10 years per 1000 children is $2.4 .^{3}$ And the incidence per 1000 live births is 2 to 3 children. ${ }^{4} \mathrm{CP}$ can be classified on the basis of severity and various 
classification systems exists on the basis of pathophysiology, etiology, and distribution of motor deficits. ${ }^{5}$ Approximately $75 \%$ of children diagnosed with CP develop spasticity, a state of increased muscle tone and exaggerated deep tendon reflexes. ${ }^{6,7}$

Spasticity is well known as motor disorder and is characterized by increase in tonic stretch reflex with exaggerated tendon jerks. ${ }^{8}$ The physical features of spasticity include pain, involuntary movements, abnormal postures and movement resistance which leads to secondary problems such as change in length of the muscle, which further causes contractures and deformity. ${ }^{9}$

MFR is the aid to mechanical, neural and psychophysiological adaptation in the myofascial system. ${ }^{10}$

It is a manipulative treatment used to help in releasing tension in the fascia. It is a safe and low load stretch which helps in releasing spasticity, muscle shortness and tightness. MFR is mainly used to reduce restrictions and barriers present in the deeper layers of fascia. This is obtained by the stretch in the muscular elastic components of the fascia and change in the viscosity of fascia. ${ }^{11}$

Faradic currents have low pulse duration and are surged; hence they are primarily used to produce contraction of innervated muscles and a tetanic contraction. The amount of chemicals formed on application of faradic currents are negligible, as the pulse duration is too small. ${ }^{12}$ The effect on musculoskeletal properties is due to surging of the faradic current as it increases the blood flow to the muscles and also enhances the contractile property of the muscle. ${ }^{13}$

Electrical muscle stimulation in the form of surged faradic current is the application of electrical current to produce a contraction of muscle. This body generated analgesic is natural and is produced normally when the body detects a painful stimulus. $^{14}$

The main aim of the study is to find out the effectiveness of Surged Faradic current and Myofascial Release technique on spasticity of lower limb muscles i.e., hamstring, calf, adductor muscles in a cerebral palsy patient.

\section{History}

The patient's age is 4 years. He has no birth history and his mother gave no abnormal pre natal, natal and post natal history. He was delivered through cesarean section. Up to 6 months he had normal growth but after that he was walking in walker at home and suddenly missed a step and fell over his head. There was no visible injury so they took care at home, but due to heavy crying he got fever and next day he started getting epileptic attack. Then they took him to the hospital and the doctors tried to get his condition in control. Still he got attack for constant 2 days with interruption due to medication. After that he was diagnosed with cerebral palsy. But due to poor family condition they could not afford costly treatments. So they took care at home and gave him medications only. Later at 3.5 years they brought him for physiotherapy treatment. But due to delay he had a lot of problems and complications. Therefore once his condition got a bit normal, we started with further treatment with MFR and SF for lower limb functioning.

\section{Methodology}

A study was carried out from $14^{\text {th }}$ December 2020 to $9^{\text {th }}$ January 2021. A 4 year old male child diagnosed with spastic cerebral palsy's was taken as the subject from Nootan College of Physiotherapy Pediatric OPD. His pre and post treatment assessment, measures, data of Modified Ashworth Scale (MAS), Pediatric Manual Muscle Testing (MMT) and Gross Motor Function (GMFM-66) were evaluated and mentioned. MFR and SF was given to the calf, hamstring and adductor muscles for 3 days a week for 4 weeks.

\section{Procedure}

Ethical approval was granted from the institutional ethical committee and the patient's mother gave an informed written consent signed. The patient demographic data and physical examination was well recorded. The treatment was first and foremost demonstrated and explained to the patient's mother. Then the patient was taken in supine position on the plinth and was made to relax. Myofascial Release 
technique and Surged Faradic current was given to the calf, hamstrings and adductors muscles for 3 days a week for 4 weeks, as shown in the Fig. 1 and 2 below, along with the conventional treatment. Pre and post treatment data is taken and mentioned in result.

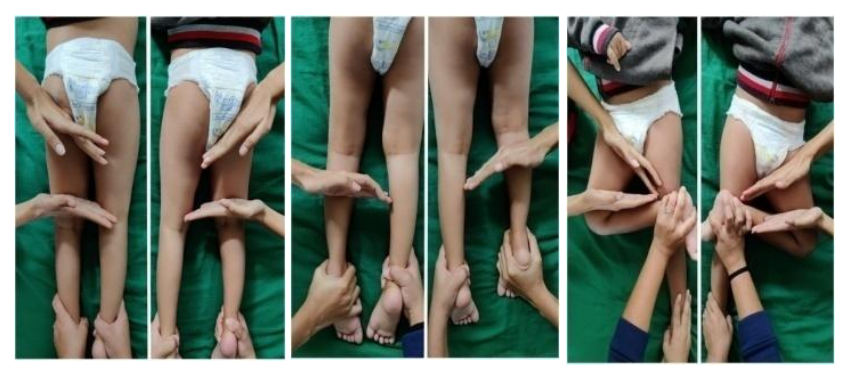

Fig.1-MFR to Hamstrings, Calf, Adductors

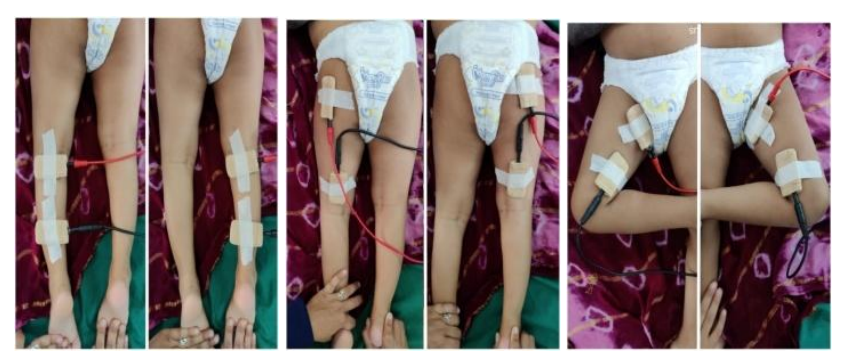

Fig.2-SF to Hamstrings, Calf, Adductors

\section{Result}

The gross motor function of case assessed by GMFM-66 increased from $45.8 \%$ at pre-test to $54.2 \%$ at post-test, MAS reduced from grade 2 at pre-test to grade 1 at post-test and pediatric MMT improved from non functional to weak functional grade, as the patient expressed improvement in standing.

\section{Discussion}

The present study was carried out to find out effectiveness of myofascial release and surged faradic current on spasticity in subjects diagnosed with spastic CP. Calf, hamstrings and adductors of hip were considered for the study as spastic subjects usually have spasticity in these muscles. A 4 year old male patient with cerebral palsy was selected as a study participant and evaluated after four weeks of MFR and SF intervention. We found significant markdown in the symptoms of this patient. This could be due to improved gross motor function, reduction in spasticity and improvement in muscle strength. Salvi Shah et al. reviewed some articles on
Myofascial release and concluded that it is very safe, effective, gentle hands-on method of soft tissue mobilization, it enhances the body's innate restorative powers by improving circulation and nervous system transmission. ${ }^{15}$ This low load sustained stretch gradually over time, allow the myofascial tissue to elongate and relax, thus allowing increased range of motion, flexibility and decreased pain. However; we are aware about the methodological limitations and inability to study the cause and effect relationship.

\section{Conclusion}

The findings of this study suggests that myofascial release was shown to reduce spasticity and surged faradic current improved muscle strength. Both in combination improved the gross motor function in spastic cerebral palsy subject but functional changes were not seen compared to conventional treatment.

\section{References}

1. Rosenbaun P, Peneth N (2007) The definition and classification of cerebral palsy. Dev Med Child Neurol 49: 8-14.

2. Sharma P, Sharma U, Kabra A (1990) Cerebral Palsy-Clinical profile and predisposing factors. Indian Pediatr 36: 1038-1042.

3. Dan B, Cheron G (2004) Reconstructing Cerebral Palsy. J PediatrNeurol 2:57-64.

4. Green LB, Hurvitz ED (2007) Cerebral palsy, physical medicine rehabilitation clinic. 859-882.

5. Jan MM (2006) Cerebral Palsy: Comprehensive Review and Update. Ann Saudi Med 26: 123-132.

6. Love SC, Valentineb JP, Blairc EM, Priced CJ, Coled JH, et al. (2001) The effect of botulinum toxin type $\mathrm{A}$ on the functional ability of the child with spastic hemiplegia a randomized controlled trial, Eur J Neurol 8: 50-58.

7. Whisler SL, Lang DM (2012); Effect of myofascial release and other advanced myofascial therapies on children with 
cerebral palsy: six case reports. Explore 8: 199-205.

8. Bovend' Eerdt TJ, Newman M, Barker K, Dawes H, Minelli C, Wade DT. The effects of stretching in spastic-ity: a systematic review. Archives of physical medicine and rehabilitation. 2008 Jul 1;89(7):1395-406.

9. Haselkorn J, Loomis S. Multiple Sclerosis and Spasticity. Phys Med Rehabil Clin N. 2005; 16:467-481.

10. Barnes JF (1995) Myofascial Release-The Missing Link in Your Treatment.

11. Gregson JM, Leathley M, Moore P, Sharma AK, Smith TL, et al. (1999) Reliability of the Tone Assessment Scale and the Modified Ashworth Scale as clinical tools for assessing poststroke spasticity. Arch Phys Med Rehabil 80: 1013-1016.

12. Robertson V, Ward A, Low J, Reed A. Electrotherapy Explained: Principles and Practice. 4th edition; 2005.

13. Mehta K, Adodariya R, Sorani D. A Comparative Study To Determine The Effectiveness Of Low Level Laser Therapy And Strong Surge Faradic Current On Trapezius Spasm. Natl J Integr Res Med 2020; Vol.11(3): 33-38.

14. Foster A,Palastanga N. Clayton's Electrotherapy- Theory and Practice. 9th ed .Delhi. A.I.T.B.S. 2006.

15. Salvi Shah, AktaBhalara (2012) Myofascial Release. International Journal of Health Sciences \& Research 2. 